International Review of Research in Open and Distributed Learning Volume 22, Number 1

February - 2021

\title{
Editorial - Volume 22, Issue 1
}

Dietmar Kennepohl

Associate Editor, Athabasca University

Welcome to our first issue of 2021! I want to start off by noting that last year IRRODL marked its $20^{\text {th }}$ anniversary with its first issue coming out in June 2000. The Editor at the time was Peter Cookson who was Professor of Distance Education and Associate Vice President, Academic at Athabasca University. He wrote about the aspirations of the journal in that very first editorial. He emphasized that IRRODL is a “... journal in which readers can inform themselves about distance education developments in theory, research, and best practice. Our aim is to have all three elements present in every issue." I believe this is something that has been achieved for every issue these last two decades including this issue. To help us celebrate, we have included a special commissioned article by Debra Dell that provides an integrative-retrospective analysis of highly-cited articles from past issues (2000-2020) of this journal. A top 10 most cited list of IRRODL articles is presented which is then used to identify themes to frame a discussion of the key topics in presentday online and distributed learning research and pedagogy. We have kept this article as the final contribution to this issue as sort of icing on our $\mathbf{2 0}^{\text {th }}$ anniversary cake. However, before you go there, I want to draw your attention to the other layers (submissions) in this cake (issue).

In our first paper, Datt and Singh explore learners' awareness of, and satisfaction with, the e-services provided at an open university showing that gender, age, and education level were influential. For example, learners with higher maturity and education levels were more aware of available services.

Cheng, Liao, and Yu present a study of $5^{\text {th }}$ grade students in an online group study robotics course, which increases participant reasoning, probabilistic reasoning, and ability to analyze a problem. The learning environment created combines real-world and digital-world resources, and can enhance the effectiveness of learning among students from a remote area.

In the following study, Luik and Lepp explore the main motivation clusters of participants in a computer programming MOOC, to compare how these clusters differed in terms of intention to complete versus actual completion rate. Interestingly, the completion rate was the lowest in the over-motivated cluster.

Olatunji and Adebisi offer a direct comparison of single- and dual-mode institutions by examining the similarities and differences in the processes and facilities for distance education at the National Open University of Nigeria and Obafemi Awolowo University, Ile-Ife. The study emphasized the universal value of blended learning and promoting ICT-driven distance education.

We are then provided with a cross-institutional evaluation and analysis of a pilot implementation of open educational resources across multiple disciplines by Oelfke, Sadowski, Ramseier, Iremonger, 
Volkert, Dykman, Kuhl, and Baumann. The survey considered creation and implementing courses (faculty), as well as perspectives on their benefits and use (students).

In the next article, Refae, Kaba, and Eletter investigate the impact of demographic characteristics on academic performance in comparing face-to-face with distance learning. Student performance in distance learning was found to be better and the authors suggest distance learning be considered as a component in any learning program.

Amzalag and Shapira demonstrate ways that online contact can be used to promote acquaintance and reduce stereotypes and prejudices among teachers from different groups in Israeli society. Findings indicated that upon program completion, participants were more respectful towards one another and open to multiculturalism than pre-program.

First-generation students in distance education programs may be at particular risk of lacking the necessary social capital to thrive in university. Brubacher and Silinda suggest that university guidance from family members may actually serve as a protective factor against potential challenges that can impact students' academic adjustment, a protective factor that first-generation students are less likely to have.

In the following study, Li and Wang examine the return to distance higher education by students in different academic disciplines. While return rates in face-to-face higher education are generally higher some differences could be explained by factors like labour market or disciplinary considerations (e.g., availability of laboratories).

With last year's arrival of COVID-19, the approach to open and distributed learning has been of significant relevance globally. These last three research articles may be of particular interest to our colleagues new to moving beyond just in-person classroom activities. First, data results in this next study can be considered good news for many educators during the pandemic attempting to determine if students would be put at a disadvantage by using one learning mode instead of another. Griffith, Faulconer, and McMasters report no significant difference regarding end of course grades, grade distribution or pass rates between online, video synchronous learning (classroom and home), or traditional classroom. Then, to aid designers, teachers, and users, Marciniak and Rivera present and validate a system, comprising of 43 assessment indicators, designed to evaluate the quality of online didactic materials and guide both in their creation and selection. Finally, Kamble, Gauba, Desai, and Golhar endeavor to understand the perceptions of learners at a university in India in the context of the sudden transition from traditional face-to-face learning to an instructor-led online learning environment (OLE). The study provides some initial practical insight and context around issues including infrastructure readiness for remote learners, acceptance, and adoption of OLE by faculty instructors, organizational support, and facilitating conditions.

The subsequent contribution comes to us as a book review. It will encourage those IRRODL readers interested in massive open online courses (MOOC) to think about them more deeply and internationally (particularly outside the global North). Perris provides us with an outstanding review and summary of the edited book, MOOCs and Open Education in the Global South: Challenges, Successes and Opportunities (Zhang, Bonk, Reeves, \& Reynolds, 2020). 
Lastly, we are provided a strong close to this issue with two thought-provoking Notes From the Field. First, Keshavarz and Ghoneim describe building a MOOC course for educators in Austria and the development of medical education for universities in Iran using Tony Bates' open book, Teaching in a Digital Age: Guidelines for Designing Teaching and Learning, as their inspiration and guide. Second, as stated earlier, Dell provides us with that icing to the journal's anniversary cake with an excellent look back at the popular (most downloaded) IRRODL articles. It is both a meaningful retrospective for the seasoned distance educator, as well as a broad overview that will be of interest to those who are new to the field of online learning. Enjoy and Happy $20^{\text {th }}$ Anniversary IRRODL!

\section{Athabasca}

University

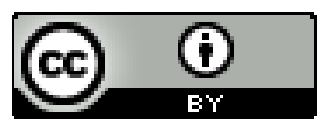

